\title{
Thrombocytopenia related to multiple organ failure (TAMOF) related to extracorporeal circulation in cardiac surgery in paediatrics
}

\author{
Vera EF*, Adrian C and Lourdes M \\ Hospital Infantil De México “Federico Gómez”, Mexico
}

\begin{abstract}
Aims and objectives: To determine the frequency of thrombocytopenia associated multi organ failure without infection criteria and its impact on the evolution and survival of patients undergoing cardiac surgery with extracorporeal circulation and prognosis.

Methods: Longitudinal, prospective, observational study to determine the frequency in the presentation of thrombocytopenia associated with multiple organ failure in patients undergoing cardiac surgery under extracorporeal circulation without positive infection rates, admitted to the intensive care unit surgical (ICU). and its impact in the evolution of these patients in the Hospital Federico Gómez.

Results: A total of 47 patients under extracorporeal circulation were analysed. Proportion for low cardiac output syndrome $23 \%$ ( $\mathrm{n}=11$ ) being this complication most frequent presented by our patients, with a direct relationship to the appearance of TAMOF with a $\mathrm{p}<0.05$, there is a direct relationship between the appearance of TAMOF in patients with $>140$ minutes of extracorporeal circulation time, the presence of deep hypothermia, lactate more than 5 mmol / L on admission, a PSOFA score of more than 8 points, and a higher score on the RASCH risk scale with a $p<0.05$. There was a significant difference with a $p<0.05$ in the days of stay in therapy intensive, and mortality among patients who developed TAMOF and those who did not.

Conclusions: The incidence of TAMOF associated with extracorporeal circulation during cardiac surgery in children and its role in impoverishment within the prognosis makes it important to identify this entity to establish action measures with appropriate therapies for these patients. It is it is necessary to normalize the ADAMTS 13 activity tests in children undergoing extracorporeal circulation.
\end{abstract}

\section{Introduction}

Thrombocytopenia related to multiple organ failure (TAMOF) is a complication associated with sepsis, due to the decrease in the activity of factor ADAMTS 13, which is a metalloprotease that breaks the structure of von Willebrand factor, which leads to thrombotic microangiopathy microvascular ischemia, thrombocytopenia and intravascular haemolysis with subsequent organ dysfunction and impoverishment of the patient's prognosis. This entity has been recognized in recent years, by to the exposure of blood flow to artificial membranes, devoid of the biological characteristics of the vascular endothelium, that favour the activation of inflammatory response mechanisms such as neutrophil chemotaxis, and activation of the pathways of coagulation [1-5].

There exist a few studies of TAMOF related to cardiac surgery in paediatrics, one of them is that of Kawai et al, he conduce the studied in a single centre with a series of cases of patients with TAMOF treated in combination with ECMO and plasmapheresis; recently there is another retrospective study, that of Mei Chong in Pittsburg with a $n=41$ patients, with an average age of 0.6 years ( $0-17$ years), they made the biochemical diagnosis of TAMOF based on the decrease in the activity of ADAMTS13, with the intervention of plasmapheresis and ECMO, reporting a general survival of $53.7 \%, 73.3 \%$ for those with heart failure, $34.8 \%$ for those with congenital heart disease, and $100 \%$ for other types of heart disease $(\mathrm{p}=0.016)$ Federico Gómez Children's Hospital in Mexico, is a congenital heart disease reference centre; in 2018, 235 cardiovascular interventions were carried out, 155 were performed under extracorporeal circulation, so it is essential to establish the incidence of thrombocytopenia associated with multiple organ failure. in these patients as well as the impact on the prognosis and their evolution.

\section{Physiology of thrombocytopenia associated with multiple organ failure}

Thrombocytopenia associated multiple organ failure (TAMOF) is a clinical phenotype that encompasses a spectrum of syndromes associated with microvascular thrombosis, one of them thrombotic microangiopathies with thrombotic thrombocytopenic purpura / haemolytic uremic syndromes and intravascular coagulation [6-8].

TAMOF is characterized by thrombocytopenia with progression to multiple organ failure in critically ill patients. The decrease in platelet counts by consumption reflects their involvement in the origin of disseminated microvascular thrombosis, which lead to ischemia and organic dysfunction [8-13].

ADAMTS-13 is a metalloprotease with regulatory action of microvascular thrombosis by excision of the von Willebrand

${ }^{\star}$ Correspondence to: Emanuelle Fernandez Vera, Hospital Infantil De México "Federico Gómez", Mexico, E-mail: efv_35@hotmail.com

Received: February 27, 2020; Accepted: March 18, 2020; Published: March 25, 2020 
coagulation factor (VWF) making it smaller and less hemostatically active multimers. Within the pathophysiology of thrombotic thrombocytopenic purpura and thrombotic microangiopathy, it has been attributed to deficiency of ADAMTS-13 levels at $<10 \%$ of normal activity and an inability to cleave high molecular weight VWF factor, platelets they adhere to ultra-large VWF multimers (ULVWF) that are not cleaved and form microvascular aggregates in endothelial cells, resulting in microvascular occlusions that are rich in platelets and $\mathrm{FvW}$, and lead to generalized thrombosis with subsequent organ dysfunction [13-20].

\section{Methods}

Longitudinal, prospective, observational study to determine the frequency in the presentation of thrombocytopenia associated with multiple organ failure in patients undergoing cardiac surgery under extracorporeal circulation without positive infection rates, admitted to the intensive care unit surgical (ICU). and its impact in the evolution of these patients in the Hospital Federico Gómez.

\section{Primary outcome}

To determine the frequency of thrombocytopenia associated multi organ failure without infection criteria and its impact on the evolution and survival of patients undergoing cardiac surgery with extracorporeal circulation and prognosis.

\section{Statistical analysis}

The collected data were entered into a database using the Microsoft Excel 2013 program and analysed in the STATA program.

Univariate analysis: measures of central tendency and dispersion of quantitative variables were obtained, while relative frequencies were calculated from qualitative variables.

Bivariate analysis: For the correlation between the exposure time to extracorporeal circulation pump, as well as the clamping time, such as the appearance of thrombocytopenia associated with multiple organ failure, the initial sofa and maximum sofa as well as for age and initial diagnosis the association tests between two variables with independent means of $\mathrm{chi}^{2}$ and $\mathrm{t}$ of student were used.

\section{Results}

Cardiac surgery was analysed from January to April 2019 with the following epidemiological results: 66 surgeries were performed, 29 male patients representing $43 \%$ and 37 female patients representing $53 \%$, the average age of surgery was 28.8 months.

With regard to pre-surgical diagnoses, the most frequent was interventricular communication with $(\mathrm{n}=18)$ the interventricular defect closure surgeries representing a proportion of $27 \%$ of the total surgeries, the surgical risk based on the RACHS scale, the most frequent risk was RACHS 2 with 30 surgeries representing $45.4 \%$, RACHS 18.1\%, RACHS $331.82 \%$ and for RACHS 4 4.5\% (Table 1).

Table 1. Patient's diagnosis

\begin{tabular}{|l|l|l|l|}
\hline Cardiopathy & $\mathbf{n}=$ & Cardiopathy & $\mathbf{n =}$ \\
\hline Interventricular communication & 18 & Total Anomalous pulmonary veins connection & 8 \\
\hline Fallot tetralogy & 2 & Great vessel transposition & 3 \\
\hline Persistent arteriosus ductus & 9 & Interauricular communication & 3 \\
\hline Tricuspid atresia & 7 & Atrioventricular canal & 1 \\
\hline Pulmonary atresia/stenosis & 11 & Common arterial trunk & 1 \\
\hline Aortic stenosis & 1 & Myocardiopathy & 2 \\
\hline
\end{tabular}

$\mathrm{Chi}^{2}$ and $\mathrm{t}$ student tests were used to statistically relate the presence of TAMOF with sociodemographic variables, the same analysis was conduce with related to extracorporeal circulation (circulation time, clamping and circulatory arrest) as well as follow-up for the variables within the intensive surgical therapy (Table 2 and Table 3 ) finding an incidence of TAMOF of $4.2 \%$ with an associated mortality of $50 \%$, related to a longer hospital stay and impoverishment of the clinical prognosis.

\section{Discussion}

For this study and in our Hospital Federico Gómez, the mortality rate for cardiac surgery corresponds to $6 \%$, which is discreetly higher than the one reported in the world literature from 4.5 to $5.5 \%$, within the cardiological diagnoses our population has the same characteristics as reported worldwide, because the most frequent diagnosis was the interventricular communication in its different forms $(n=21)$ in a proportion of $34 \%$, with respect to the age of the patient undergoing surgery, surgeries are performed on average at 20 months of age, which in most of them represents a delay in surgical management. Regarding the exposure to extracorporeal circulation, our population has longer time variables than recommendation for these procedure (circulation time, clamping time, time of cardiac arrest) longer for them, which represents a risk factor associated with more morbidity and a higher mortality, with a positive association between the duration of these procedures and the incidence of low cardiac output syndrome, how has been demonstrated in our cohort that syndrome present in a frequency of $11 / 47,(23 \%)$, which is comparable with reported in the literature, and very important it was the most frequently complication associated in our patients with TAMOF $(\mathrm{X} 2, \mathrm{p}<0.05)$ [17].

There are a direct association between a total circulation time $>140$ minutes with the presentation of TAMOF, other statistically significant associations were the presence of deep hypothermia, lactate of more than $5 \mathrm{mmol} / \mathrm{L}$ at the admission to ICU., a PSOFA score of more than 8 points, as well as a higher score on the RACHS risk scale $\left(\mathrm{X}^{2}, \mathrm{p}<0.05\right)$ There was a significant difference $(\mathrm{p}=<0.05)$ in the days of ICU stay (20.5 vs. 4.2 days).

There is no reported incidence in the literature of thrombocytopenia associated with multiple organ failure in paediatric patients undergoing extracorporeal circulation so our study sets the basis for this measure for this pathology, we found a frequency of $4.2 \%$, with an associated mortality of $50 \%$, which corresponds to what is reported in the literature in the study by Chong et al. There was a statistically significant difference between the mortality of patients who developed TAMOF $(1 / 2)$ and those who did not develop it $(\mathrm{p}=<0.05)$.

\section{Conclusions}

The frequency of TAMOF associated with extracorporeal circulation during cardiac surgery and its role in impoverishment within the patient's prognosis makes it important to identify this phenotypic response of thrombotic microangiopathy to establish action measures with appropriate therapies for this group of patients.

It is necessary to standardize the evidence of the activity levels of the ADAMTS 13 factor in children undergoing extracorporeal circulation and mainly in those patients who encounter the risk factors described in this study. Likewise, in this study it was found that extracorporeal circulation times longer than those recommended for this type of procedures are translated as greater comorbidities such as the presence of low cardiac output syndrome. 
Vera EF (2020) Thrombocytopenia related to multiple organ failure (TAMOF) related to extracorporeal circulation in cardiac surgery in paediatrics

Table 2. TAMOF contingency table for demographic and clinical evolution variables

\begin{tabular}{|c|c|c|c|c|c|c|}
\hline Variable & & TAMOF $n=2$ & No TAMOF $n=45$ & $\mathrm{Ch}^{2}$ & $P$ value & IC \\
\hline Gender & $\begin{array}{l}\text { Male } \\
\text { Female }\end{array}$ & $\begin{array}{l}0 \\
2\end{array}$ & $\begin{array}{l}22 \\
23\end{array}$ & 1.832 & 0.175 & $95 \%$ \\
\hline Age & $\leq 6$ months $\geq 6$ months & $\begin{array}{l}1 \\
1\end{array}$ & $\begin{array}{l}26 \\
19\end{array}$ & 0.047 & 0.828 & $95 \%$ \\
\hline Extracorporeal Circulation & $\begin{array}{l}\leq 140 \mathrm{~min} \\
\geq 140 \mathrm{~min}\end{array}$ & $\begin{array}{l}1 \\
1\end{array}$ & $\begin{array}{c}41 \\
4\end{array}$ & 3.404 & 0.065 & $95 \%$ \\
\hline Aortic clamping & $\leq 40 \min \geq 40 \mathrm{~min}$ & $\begin{array}{l}0 \\
2\end{array}$ & $\begin{array}{l}20 \\
25\end{array}$ & 1.547 & 0.214 & $95 \%$ \\
\hline Cardiac Arrest & $\begin{array}{l}\text { Yes } \\
\text { No }\end{array}$ & $\begin{array}{l}1 \\
1\end{array}$ & $\begin{array}{c}41 \\
4\end{array}$ & 3.40 & 0.065 & $95 \%$ \\
\hline Deep hypothermia & $\begin{array}{l}\text { Yes } \\
\text { No }\end{array}$ & $\begin{array}{l}2 \\
0\end{array}$ & $\begin{array}{c}1 \\
44\end{array}$ & 30.634 & 0.001 & $95 \%$ \\
\hline SBGC * & $\begin{array}{l}\text { Yes } \\
\text { No }\end{array}$ & $\begin{array}{l}2 \\
0\end{array}$ & $\begin{array}{c}9 \\
36\end{array}$ & 6.836 & 0.009 & $95 \%$ \\
\hline Haemorrhagic shock & $\begin{array}{l}\text { Yes } \\
\text { No }\end{array}$ & $\begin{array}{l}0 \\
0\end{array}$ & $\begin{array}{c}0 \\
45\end{array}$ & 0.031 & 0.859 & $95 \%$ \\
\hline Septic shock & $\begin{array}{l}\text { Yes } \\
\text { No }\end{array}$ & $\begin{array}{l}0 \\
2\end{array}$ & $\begin{array}{c}43 \\
2\end{array}$ & 0.092 & 0.761 & $95 \%$ \\
\hline Serum lactate & $\leq 5 \mathrm{mmol} / \mathrm{L} \geq 5 \mathrm{mmol} / \mathrm{L}$ & $\begin{array}{l}0 \\
2\end{array}$ & $\begin{array}{c}37 \\
8\end{array}$ & 7.72 & 0.005 & $95 \%$ \\
\hline Initial SOFA score & $\begin{array}{l}\geq 8 \text { points } \\
<8 \text { points }\end{array}$ & $\begin{array}{l}2 \\
0\end{array}$ & $\begin{array}{c}1 \\
44\end{array}$ & 30.637 & 0.001 & $95 \%$ \\
\hline Maximum SOFA score & $\geq 8$ points $<8$ points & $\begin{array}{l}2 \\
0\end{array}$ & $\begin{array}{l}23 \\
22\end{array}$ & 1.838 & 0.175 & $95 \%$ \\
\hline Risk scale & $\begin{array}{l}\text { RACHS } 1 \\
\text { RACHS } 2 \\
\text { RACHS } 3 \\
\text { RACHS } 4\end{array}$ & $\begin{array}{l}0 \\
0 \\
0 \\
2\end{array}$ & $\begin{array}{c}4 \\
25 \\
15 \\
1\end{array}$ & 30.637 & 0.001 & $95 \%$ \\
\hline ICU Discharge & $\begin{array}{l}\text { Yes } \\
\text { No }\end{array}$ & $\begin{array}{l}1 \\
1\end{array}$ & $\begin{array}{c}1 \\
44\end{array}$ & 30.637 & 0.008 & $95 \%$ \\
\hline
\end{tabular}

Table 3. Comparison of means for independent variables in patients with TAMOF

\begin{tabular}{|c|c|c|c|c|c|}
\hline Variable & $\begin{array}{c}\text { TAMOF } \\
n=2\end{array}$ & $\begin{array}{c}\text { No TAMOF } \\
\mathbf{N}=45\end{array}$ & Dif. Med. & P value & IC \\
\hline Age & 27 months & 62.04 months & 35.04 & 0.45 & $41.61-79.48$ \\
\hline Aortic clamping & $82 \mathrm{~min}$ & $53.31 \mathrm{~min}$ & -28.68 & 0.098 & $47.49-61.56$ \\
\hline Temperature & $32^{\circ} \mathrm{C}$ & $31.07^{\circ} \mathrm{C}$ & -0.92 & 0.716 & $30.10-32.13$ \\
\hline Cardiac Arrest & $38 \mathrm{~min}$ & $5.11 \mathrm{~min}$ & -32.89 & 0.012 & $1.08-11.93$ \\
\hline $\begin{array}{l}\text { Extracorporeal } \\
\text { circulation }\end{array}$ & $95.5 \mathrm{~min}$ & $96.91 \mathrm{~min}$ & 1.41 & 0.958 & $85.94-107.75$ \\
\hline Inital SOFA score & 5.5 puntos & 5.8 puntos & 0.36 & 0.666 & $5.51-6.19$ \\
\hline Maximum SOFA & 7.5 puntos & 9.31 puntos & 1.81 & 0.489 & $8.18-10.28$ \\
\hline Days in ICU & 20.5 días & 4.2 días & -16.3 & 0.001 & $3.38-6.40$ \\
\hline Serum Lactate & $7.35 \mathrm{mmol} / \mathrm{L}$ & $3.85 \mathrm{mmol} / \mathrm{L}$ & -3.49 & 0.082 & $3.18-4.82$ \\
\hline Platelets account & $73.5 \mathrm{cell} / \mathrm{mm}^{3}$ & 218.4 cell $/ \mathrm{mm}^{3}$ & 144.92 & 0.013 & $188.02-236.48$ \\
\hline
\end{tabular}

\section{References}

1. Kheman RG, Bart RD, Alonzo TA (2009) Disseminated intravascular coagulation score is associated with mortality for children with shock. Intensive Care Med 35: 327 333. [Crossref]

2. Szczepiorowski ZM, Winters JL, Bandarenko N (2010) Guidelines on the use of therapeutic apheresis in clinical practice-evidence-based approach from the Apheresis Applications Committee of the American Society for Apheresis. J Clin Apheresis 25: 83-177. [Crossref]

3. Moore JC, Hayward CP, Warkentin TE, Kelton JG (2001) Decreased von Willebrand factor protease activity associated with thrombocytopenic disorders. Blood 15: 98:1842-1846. [Crossref]

4. Ono T, Mimuro J, Madoiwa S, Soejima K, Kashiwakura Y, et al. (2005) Severe secondary deficiency of von Willebrand factor-cleaving protease (ADAMTS13) in patients with sepsis-induced disseminated intravascular coagulation: Its correlation to development of renal failure. Blood 27: 03. [Crossref]

5. Edmunds LH (1998) Jr: Inflammatory response to cardiopulmonary bypass. Ann Thorac Surg 66: S12. [Crossref]
6. Warren JS, Ward PA (2001) The inflammatory response. In: Beutler E, Coller BS Lichtman MA, et al. (eds): Williams Hematology, 6th ed. New York, McGraw-Hill. P: 67.

7. Cugno $\mathrm{M}$, Nussberger $\mathrm{J}$, Biglioli $\mathrm{P}$, Giovagnoni $\mathrm{MG}$, Gardinali $\mathrm{M}$, et al (1999) Cardiopulmonary bypass increases plasma bradykinin concentrations. Immunopharmacology. 43: 145-147. [Crossref]

8. Levy JH, Tanaka KA (2003) Inflammatory response to cardiopulmonary bypass. Ann Thorac Surg 75: S715-20. [Crossref]

9. RAHE-Meyer N, Solomon C, Tokuno ML, Winterhalter M, Shrestha M, et al. (2010) Comparative assessment of coagulation changes induced by two different types of heart-lung machine. Artif Organs 34: 3-12. [Crossref]

10. Fromes Y, Gaillard D, Ponzio O, Chauffert M, Gerhardt MF, et al. (2002) Reduction of the inflammatory response following coronary bypass grafting with total minimal extracorporeal circulation. Eur J Cardiothorac Surg 22: 527-533. [Crossref]

11. Rinder H, Bonan J, Rinder C, Ault K, Smith B (1991) Activated and unactivated platelet adhesion to monocytes and neutrophils. Blood 78: 1760-1769. [Crossref] 
12. Neumann FJ, Marx N, Gawaz M, Brand K, Ott I, et al. (1997) Induction of cytokine expression in leukocytes by binding of thrombin-stimulated platelets. Circulation 95: 2387-2394. [Crossref]

13. Millar Jonathan (2016) The inflammatory response to extracorporeal membrane oxygenation (ECMO): a review of the pathophysiology. Critical Care 20: 387. [Crossref]

14. Ortega Loubon Christian (2015) Extracorporeal Circulation in Cardiac Surgery Inflammatory response, controversies and Future Directions. International Archives of Medicine.

15. Carcillo Joseph A (2017) Pathophysiology of Pediatric Multiple Organ Dysfunction Syndrome. Pediatr Crit Care Med 18: S32-S45. [Crossref]

16. Chong Mei (2017) Use of Therapeutic Plasma exchange during extracorporeal life support in critically ill cardiac children with Thrombocytopenia-associated MultiOrgan Failure. Frontiers in paediatrics. [Crossref]
17. Nguyen TC, Carcillo JA (2006) Bench-to-bedside review: thrombocytopeniaassociated multiple organ failure - a newly appreciated syndrome in the critically ill. Crit Care 10: 235 .

18. Johnton JA (2004) Importance of organ dysfunction in determining hospital outcomes in children. J Pediatr 144: 595-601. [Crossref]

19. Wernovsky G, WypIj D, Jonas R, Mayer J, Hanley F, et al. (1995) Postoperative course and hemodynamic profile after the arteial switch operation in neonate and infants. A comparison of low flow cardiopulmonary bypass and circulatory arrest. Circulation 92: 26-35. [Crossref]

20. Rothenburger M. Tjan TD, Schneider M (2003) The impact of the pro an antiinflammatory immune response on ventilation time after cardiac surgery. Cytometry $B$ CyTIM 53: 7 0-4. [Crossref]

Copyright: (C2020 Vera EF. This is an open-access article distributed under the terms of the Creative Commons Attribution License, which permits unrestricted use, distribution, and reproduction in any medium, provided the original author and source are credited. 